\title{
Clinical profile and outcome of surgical treatment of perforated peptic ulcers in Northwestern Tanzania: A tertiary hospital experience
}

Phillipo L Chalya ${ }^{1 *}$, Joseph B Mabula ${ }^{1 \dagger}$, Mheta Koy ${ }^{2 \dagger}$, Mabula D Mchembe ${ }^{3 \dagger}$, Hyasinta M Jaka ${ }^{2 \dagger}$, Rodrick Kabangila ${ }^{2 \dagger}$, Alphonce B Chandika $^{1+}$ and Japhet M Gilyoma ${ }^{1+}$

\begin{abstract}
Background: Perforated peptic ulcer is a serious complication of peptic ulcers with potential risk of grave complications. There is paucity of published reports on perforated peptic ulcer disease in our local environment. This study was conducted to evaluate the clinical presentation, management and outcome of patients with peptic ulcer perforation in our setting and to identify predictors of outcome of these patients.

Methods: This was a combined retrospective and prospective study of patients who were operated for perforated peptic ulcers at Bugando Medical Centre between April 2006 and March 2011. Data were collected using a pretested and coded questionnaire and analyzed using SPSS computer software version 15.0. Ethical approval to conduct the study was obtained from relevant authority before the commencement of the study.

Results: A total of 84 patients were studied. Males outnumbered females by a ratio of 1.3: 1. Their median age was 28 years and the modal age group was 21-30 years. The median duration of illness was 5.8 days. The majority of patients (69.0\%) had no previous history of treatment for peptic ulcer disease. The use of non-steroidal antiinflammatory drugs, alcohol and smoking was reported in $10.7 \%, 85.7 \%$ and $64.3 \%$ respectively. Eight (9.5\%) patients were HIV positive with a median CD4 count of 220 cells/ $\mu$ l. Most perforations were located on the duodenum $\{90.4 \%$ ) with the duodenal to gastric ulcers ratio of 12.7: 1. Graham's omental patch (Graham's omentopexy) of the perforations was performed in $83.3 \%$ of cases. Complication and mortality rates were $29.8 \%$ and $10.7 \%$ respectively. The factors significantly related to complications were premorbid illness, HIV status, CD 4 count $<200 \mathrm{cells} / \mu \mathrm{l}$, treatment delay and acute perforation $(P<0.001)$. Mortality rate was high in patients who had age $\geq 40$ years, delayed presentation (>24 hrs), shock at admission (systolic BP $<90 \mathrm{mmHg}$ ), HIV positivity, low CD4 count $(<200$ cells/ $\mu$ l), gastric ulcers, concomitant diseases and presence of complications $(P<0.001)$. The median overall length of hospital stay was 14 days. Excellent results using Visick's grading system were obtained in $82.6 \%$ of surviving patients.

Conclusion: Perforation of peptic ulcer remains a frequent clinical problem in our environment predominantly affecting young males not known to suffer from PUD. Simple closure with omental patch followed by Helicobacter pylori eradication was effective with excellent results in majority of survivors despite patients' late presentation in our center.
\end{abstract}

Keywords: Perforated peptic ulcers, clinical profile, surgical management, outcome, Tanzania

\footnotetext{
* Correspondence: drphillipoleo@yahoo.com

† Contributed equally

'Department of Surgery, Weill-Bugando University College of Health

Sciences, Mwanza, Tanzania

Full list of author information is available at the end of the article
} 


\section{Background}

Peptic ulcer disease (PUD) represents a worldwide health problem because of its high morbidity, mortality and economic loss [1]. In the United States, approximately 5 million adults suffer annually from peptic ulcer disease and 500.000 new cases with 4 million recurrences are reported each year [1,2].

Globally, the incidence of peptic ulcer disease has fallen in recent years [3-5]. Despite this and recent advances in both diagnosis and management of peptic ulcer disease, namely the improvement in endoscopic facilities, eradication of $\mathrm{H}$. pylori and the introduction of the proton pump inhibitors, complications such as peptic ulcer perforation remain a substantial healthcare problem. This may be due to an increase in the risk factors for peptic ulcer complications $[3,6]$.

Peptic ulcer perforation is a serious complication which affects almost $2-10 \%$ of peptic ulcer patients on the average $[7,8]$. Peptic ulcer perforation presents with an overall mortality of $10 \%$ [9] although some authors report ranges between $1.3 \%$ and $20 \%$ [10,11]. Being a life threatening complication of peptic ulcer disease, it needs special attention with prompt resuscitation and appropriate surgical management if morbidity and mortality are to be avoided $[3,11]$.

The pattern of perforated PUD has been reported to vary from one geographical area to another depending on the prevailing socio-demographic and environmental factors [12]. In the developing world, the patient population is young with male predominance, patients present late, and there is a strong association with smoking [13]. In the west the patients tend to be elderly and there is a high incidence of ulcerogenic drug ingestion [14].

The diagnosis of perforated PUD poses a diagnostic challenge in most of cases. The spillage of duodenal or gastric contents into peritoneal cavity causing abdominal pain, shock, peritonitis, marked tenderness and decreased liver dullness offers little difficulty in diagnosis of perforations [15].The presence of gas under the diaphragm on plain abdominal erect X-ray is diagnostic in $75 \%$ of the cases [16].

Since the first description of surgery for acute perforated peptic ulcer disease, many techniques have been recommended. The recent advances in antiulcer therapy have shown that simple closure of perforation with omental patch followed by eradication of $H$. Pylori is a simple and safe option in many centers and have changed the old trend of truncal vagotomy and drainage procedures [17]. The definitive operation for perforated PUD is performed by few surgeons.

Delay in diagnosis and initiation of surgical treatment of perforated PUD has been reported to be associated with high morbidity and mortality after surgery for perforated PUD $[4,17]$. Early recognition and prompt surgical treatment of perforated PUD is of paramount importance if morbidity and mortality associated with perforated PUD are to be avoided [4,11]. A successful outcome is obtained by prompt recognition of the diagnosis, aggressive resuscitation and early institution of surgical management.

Little work has been done on the surgical management of perforated peptic ulcer disease in our local environment despite increase in the number of admissions of this condition. The aim of this study was to describe our experience on the surgical management of perforated peptic ulcer disease in our local environment outlining the incidence, clinical presentation, management and outcome of patients with peptic ulcer perforation in our setting and to identify predictors of outcome of these patients.

\section{Methods}

\section{Study design and setting}

This was a combined retrospective and prospective study of patients operated for peptic ulcer perforations at Bugando Medical Centre (BMC) in Northwestern Tanzania from April 2006 to March 2011. BMC is a tertiary care hospital in Mwanza City that also receives patients from its six neighboring regions around Lake Victoria. It is a 1000 bed, consultant and teaching hospital for the Weill-Bugando University Collage of Health Sciences (WBUCHS) and other paramedics.

\section{Study subject}

The subjects of this study included all patients who were operated for perforated peptic ulcers at Bugando Medical Centre during the period under study. Patients with incomplete data were excluded from the study. Patients treated conservatively and those who failed to consent for HIV infection were also excluded from the study. The details of patients who presented from April 2006 to March 2008 were retrieved retrospectively from patient registers kept in the Medical record departments, the surgical wards, and operating theatre. Patients who presented to the A \& E department between April 2008 and March 2011 were prospectively enrolled in the study after signing an informed written consent for the study. A detailed history and thorough physical examination were followed by investigations like full blood count, blood grouping, serum urea, serum creatinine and random blood sugar. Patients were also screened for HIV infection using rapid test/ELISA test. A determination of CD 4 count was also performed in all HIV positive patients. Radiological investigations like $\mathrm{X}$-ray abdomen erect and chest $\mathrm{X}$-ray were done in all patients on the suspicion 
of diagnosis of perforated PUD. Other investigations included hematological profile, serum urea and electrolytes and urinalysis. The diagnosis of perforated PUD was made from history, plain abdominal and chest radiographs, and confirmed at laparotomy. Patients were put on intra-venous fluids, nasogastric suction, intravenous antibiotics and intravenous anti-ulcer drugs; adequate hydration was indicated by an hourly urine output of $30 \mathrm{ml} /$ hour. After adequate resuscitation, laparotomy was done through midline incision and identified the perforation site. Simple closure of the perforation and reinforcement with pedicled omental patch (Graham's omentopexy) was done. Thorough peritoneal lavage with 3 to 4 liters of normal saline was followed by placement of intraperitoneal drain. The operations were performed either by a consultant surgeon or a senior resident under the direct supervision of a consultant surgeon. The Boey score [11] as a tool for outcome prediction was calculated based on data recorded at the time of admission to hospital. The Boey risk stratification in perforated peptic ulcer consists of associated medical illness, preoperative shock and long-standing perforation (more than 24 hours). Preoperative shock was defined as a preoperative systolic blood pressure of less than $90 \mathrm{mmHg}$. All the patients were put on triple regime consisting of Amoxicillin (500 mg TID), Metranidazole(400 mg TID) and Omeprazole (20 mg BID), all given orally for 14 days to eradicate H. Pylori. Patients were followed up on an out patient basis for up to 12 months after surgery. Depending upon their symptoms at each visit, patients were graded using a modified Visick classification [18] as follows:-

Grade I: No symptoms, excellent results.

II: Mild symptoms, good results.

III: Moderate symptoms, easily controlled by medications.

IV: Severe symptoms, requiring constant medication or re-operation

\section{Data collection}

Data were collected using a preformed questionnaire. variables included in the questionnaire were; patient's demographic data (age, sex), associated medical premorbid illness, duration of illness, previous history of PUD, NSAID use, alcohol use and cigarette smoking, HIV status, CD 4 count, timing of surgical treatment, site of perforation, size of perforation, type of surgical procedure, postoperative complication, length of hospital stay, mortality. The duration of symptoms was defined as the time span between the initial pain perception due to perforation and the operation.

\section{Statistical analysis}

The statistical analysis was performed using statistical package for social sciences (SPSS) version 15.0 for Windows (SPSS, Chicago IL, U.S.A).The mean \pm standard deviation (SD), median and ranges were calculated for continuous variables whereas proportions and frequency tables were used to summarize categorical variables. Continuous variables were categorized. Chi-square $(\chi 2)$ test were used to test for the significance of association between the independent (predictor) and dependent (outcome) variables in the categorical variables. The level of significance was considered as $\mathrm{P}<0.05$. Multivariate logistic regression analysis was used to determine predictor variables that predict the outcome.

\section{Ethical consideration}

Ethical approval to conduct the study was obtained from the WBUCHS/BMC joint institutional ethic review committee before the commencement of the study. Patients recruited prospectively were required to sign a written informed consent for the study and for HIV testing.

\section{Results}

Out of 1124 patients who presented with peptic ulcer disease (PUD) during the study period, 96 patients underwent emergency laparotomy for perforated peptic ulcers. Of these, 8 patients were excluded from the study due to incomplete data and failure to meet the inclusion criteria. Thus, 84 patients were enrolled giving an average of 17 cases annually and represented $7.5 \%$ of cases. Of these, $18(21.4 \%)$ patients were studied retrospectively and the remaining $66(78.6 \%)$ patients were studied prospectively.

\section{Socio-demographic characteristics}

Forty-eight $(57.1 \%)$ were males and females were 36 $(42.9 \%)$ with a female ratio of $1.3: 1$. The patient's age ranged from 12 to 72 years with a median of 32.4 years. The peak incidence was in the $4^{\text {th }}$ decade (31-40 years). The majority of patients, $52(61.9 \%)$ were younger than 40 years. Most of patients, 64 (76.2\%) had either primary or no formal education and more than three quarter of them were unemployed.

\section{Clinical presentation}

The duration of symptoms ranged from 1 to 12 days with a mean duration of $6.5 \pm 2.3$ days. The median was 5.8 days. 24 (28.6\%) presented within twenty-four hours of onset of symptoms, 25 (29.8\%) between 24 and 48 hours and $30(35.7 \%)$ over 48 hours afterwards. The duration of symptoms was not documented in 5 (5.9\%) patients. The commonest presenting symptoms were sudden onset of severe epigastric pain in 82 (97.6\%), abdominal distention in $64(76.2 \%)$ and vomiting in 31 
(36.9\%) patients. Abdominal tenderness and classical signs of peritonitis were demonstrable in 74 (88.1\%) and 56(66.7\%) patients respectively (Table 1 ).

Fifty-eight (69.0\%) patients reported no previous history of treatment for peptic ulcer disease. Patients with a previous history of peptic ulcer disease had had symptoms for durations ranging from six months to 14 years and all of them were not on regular anti-ulcer therapy. Three (3.6\%) patients presented with re-perforation. Nine (10.7\%) patients reported history of recent ingestion of non-steroidal anti-inflammatory drugs (NSAIDS) for joint and back pains. Other risk factors recorded included alcohol consumption and smoking in 72 (85.7\%) and 54 (64.3\%) patients respectively. Most patients who smoked also took alcohol.

In this study, six (7.1\%) patients had associated premorbid illness namely osteoarthritis in 3 patients and hypertension, diabetes mellitus and sickle cell disease in 1 patient each respectively. Eight (9.5\%) patients were HIV positive. Of these, 3 (37.5\%) patients were known cases on ant-retroviral therapy (ARV) and the remaining $5(62.5 \%)$ patients were newly diagnosed patients. CD4+ count distribution among HIV positive patients ranged from 56 cells/ $\mu \mathrm{l}$ to 650 cells/ $\mu$ l with the mean of 236 cells $/ \mu \mathrm{l}$ and standard deviation of 86 cells $/ \mu \mathrm{l}$. The median and the mode were 220 cells $/ \mu$ l and 160 cells $/ \mu \mathrm{l}$ respectively. A total of two HIV patients $(25.0 \%)$ had CD $4+$ count below 200 cells $/ \mu$ l and the remaining 6 patients $(75.0 \%)$ had CD $4+$ count of $\geq 200$ cells/ $\mu$ l. Of the eight patients with HIV infection, six (75.0\%) patients reported to have risk factors for HIV infection. Of these, alcoholism [Odds Ratio 11.3, 95\% C.I. (8.316.7), $\mathrm{P}=0.021$ ] and multiple sexual partners [Odds Ratio 10.8, 95\% C.I. (6.7-14.9), P $=0.000$ ] were found to be independently and significantly associated with increased risk to HIV infection

\section{Radiological, operative and histopathological findings}

Seventy-nine $(94.0 \%)$ of the patients had plain abdominal and chest radiographs done, with free gas under the

\section{Table 1 Clinical presentation}

\begin{tabular}{lll}
\hline Clinical presentation & Frequency & Percentage \\
\hline Severe abdominal pain & 82 & 97.6 \\
Abdominal distention & 64 & 76.2 \\
Vomiting & 31 & 36.9 \\
Nausea & 30 & 35.7 \\
Severe dyspepsia & 28 & 33.3 \\
Constipation & 25 & 29.8 \\
Fever & 18 & 21.4 \\
Shock & 28 & 33.3 \\
Abdominal tenderness & 74 & 88.1 \\
Classical signs of peritonitis & 56 & 66.7 \\
\hline
\end{tabular}

diaphragm (pneumoperitonium) demonstrated in 52 $(65.8 \%)$ of them. All patients in this study underwent laparotomy. The time interval between the beginning of the symptoms of perforation and surgery ranged from 12 to140 hours with the median of 72 hours. The majority of patients $(76.2 \%)$ presented 48 hours or more after the onset of the symptoms of perforation. During operation, all the cases were opened through midline incision and after opening of the peritoneum, there was expulsion of gas in all cases. Most perforations were located on the duodenum $\{78,92.9 \%)$, whereas in the remaining six (7.1\%) patients had their ulcers located on the stomach. The duodenal to gastric ulcers ratio was 12.7: 1 . The majority of patients, 82 (97.6\%) had single perforation and the remaining $2(2.4 \%)$ patients had both duodenal and gastric perforations. The mean age of the patients with gastric ulcers $(56.4 \pm 12.5)$ was significantly higher than that of those with duodenal ulcers $(32.8 \pm 14.4)(\mathrm{P}=$ $0.002)$. The median size of the ulcer was $5.4 \mathrm{~mm}(2-20$ $\mathrm{mm})$. Seven $(8.3 \%)$ of the perforations were found to be sealed. Thirteen (15.5\%) of the perforations were of minimal size $(\leq 5 \mathrm{~mm})$ and sixty-four $(76.2 \%)$ were massive $(>10 \mathrm{~mm})$. All perforations were found adhered with omentum and the nature of peritoneal fluid was serosanguineous in $34(40.5 \%)$ patients, bilious in 28 (33.3\%) patients and purulent in $14(16.7 \%)$ patients. The amount of peritoneal fluid varied from 500 to $1000 \mathrm{mls}$ with a median of $564 \mathrm{mls}$. The nature of peritoneal fluid was not documented in $8(9.5 \%)$ patients. Histological examination of the biopsy specimens revealed no malignancy. All biopsies were not stained for Helicobacter pylori.

\section{Surgical treatment}

The majority of patients, 70 (83.3\%) had Graham's omental patch of the perforations with either a pedicled omental patch or a free graft of omentum. Those with sealed perforations had peritoneal lavage with warm saline and mass closure of the abdomen. One patient had truncal vagotomy and Roux-en-Y gastro-jejunostomy in addition to simple closure. One patient who had a large ulcer, which penetrated to the pancreas and caused pyloric obstruction, underwent subtotal gastrectomy.

\section{Outcome of Treatment}

Post-operative complications were recorded in 25 (29.8\%) patients. Of these, surgical site infection (48.0\%) was the most common post-operative complications (Table 2). The mean age of patients who developed complications was $52.4 \pm 16.4$ years, whereas the mean age of patients without complications was $32.6 \pm 10.2$ years. This age difference was statistically significant $(\mathrm{P}$ $=0.011$ ). The complication rates for $0,1,2$ and 3 Boey scores were $8.0 \%, 12.0 \%, 20.0 \%$ and $60.0 \%$, respectively $(\mathrm{P}=0.002$, Pearson $\chi 2$ test $)$ 
Table 2 Post-operative complications ( $\mathrm{N}=\mathbf{2 5}$ )

\begin{tabular}{lll}
\hline Complications & Frequency & Percentage \\
\hline Surgical site infections & 12 & 48.0 \\
Post-operative pyrexia & 9 & 36.0 \\
Pulmonary infection & 7 & 28.0 \\
Intra-abdominal abscess & 5 & 20.0 \\
Wound dehiscence/burst abdomen & 5 & 20.0 \\
Re-perforation & 4 & 16.0 \\
Septic shock & 3 & 12.0 \\
Enterocutaneous fistula & 3 & 12.0 \\
Peritonitis & 3 & 12.0 \\
Incisional hernia & 2 & 8.0 \\
Cardiopulmonary arrest & 2 & 8.0 \\
Acute renal failure & 1 & 4.0 \\
Paralytic ileus & 1 & 4.0
\end{tabular}

Table 3 shows predictors of complications according to univariate and multivariate logistic regression analysis. The overall length of hospital stay (LOS) ranged from 1 to 48 days with a median of 14 days. The median LOS for non-survivors was 3 days (range 1-8 days). Patients who developed complications stayed longer in the hospital and this was statistically significant $(\mathrm{P}=$ 0.005). In this study, nine patients died giving a mortality rate of $10.7 \%$. The mortality rate increased progressively, with increasing numbers of Boey scores: $0 \%$, $11.1 \%, 33.3 \%$, and $56.6 \%$ for $0,1,2$, and 3 factors, respectively $(\mathrm{P}<0.001$, Pearson $\chi 2$ test).

Table 4 shows predictors of mortality according to univariate and multivariate logistic regression analysis.

Table 3 Predictors of complications according to univariate and multivariate logistic regression analysis

\begin{tabular}{|c|c|c|c|c|c|c|}
\hline \multirow[t]{2}{*}{ Predictor(independent) variable } & \multirow[t]{2}{*}{ Complication N (\%) } & \multirow[t]{2}{*}{ No complication n (\%) } & \multicolumn{2}{|c|}{ Univariate analysis } & \multicolumn{2}{|c|}{ Multivariate analysis } \\
\hline & & & O.R. $95 \%$ C.I. & p-value & O.R. $95 \%$ C.I. & p-value \\
\hline \multicolumn{7}{|l|}{ Age (in years) } \\
\hline$<40$ & $15(28.8)$ & $37(71.2)$ & & & & \\
\hline$\geq 40$ & $10(31.2)$ & $22(68.8)$ & $3.91(0.94-5.23)$ & 0.167 & $1.23(0.93-2.34)$ & 0.786 \\
\hline \multicolumn{7}{|l|}{ Sex } \\
\hline Male & $14(29.2)$ & $36(70.8)$ & & & & \\
\hline Female & $11(30.6)$ & $25(69.4)$ & $1.87(0.22-4.88)$ & 0.334 & 3.32(0.45-4.66) & 0.937 \\
\hline \multicolumn{7}{|l|}{ Premorbid illness } \\
\hline Yes & $4(66.7)$ & $2(33.3)$ & & & & \\
\hline No & $21(26.9)$ & $57(73.1)$ & $3.54(1.33-5.87)$ & 0.012 & $5.28(2.39-6.82)$ & 0.007 \\
\hline \multicolumn{7}{|l|}{ Previous PUD } \\
\hline Yes & $7(26.9)$ & 19(73.1) & & & & \\
\hline No & 18(31.0) & $40(69.0)$ & $0.21(0.11-1.78)$ & 0.051 & $1.65(0.32-2.89)$ & 0.786 \\
\hline \multicolumn{7}{|l|}{ NSAIDs use } \\
\hline Yes & $3(33.3)$ & $6(66.7)$ & & & & \\
\hline No & $22(29.3)$ & 53(70.7) & 1.98(0.99-3.91) & 0.923 & $1.02(0.78-3.90)$ & 0.123 \\
\hline \multicolumn{7}{|l|}{ Alcohol use } \\
\hline Yes & $22(30.6)$ & $50(69.4)$ & & & & \\
\hline No & $3(25.0)$ & $9(75.0)$ & $3.05(0.19-2.86)$ & 0.054 & $0.45(0.22-5.21)$ & 0.321 \\
\hline \multicolumn{7}{|l|}{ Cigarette smoking } \\
\hline Yes & $17(31.5)$ & $37(68.5)$ & & & & \\
\hline No & $8(26.7)$ & $22(73.3)$ & $3.11(0.44-5.23)$ & 0.145 & 3.02(0.99-4.56) & 0.334 \\
\hline \multicolumn{7}{|l|}{ Treatment delay } \\
\hline$<48$ & 18(90.0) & $2(10.0)$ & & & & \\
\hline$\geq 48$ & $7(14.6)$ & $41(85.4)$ & $1.06(1.01-5.45)$ & 0.021 & $0.23(0.11-0.95)$ & 0.003 \\
\hline \multicolumn{7}{|l|}{ HIV status } \\
\hline Positive & $6(75.0)$ & $2(25.0)$ & & & & \\
\hline Negative & $19(25.0)$ & $57(75.0)$ & $2.87(1.22-4.97)$ & 0.023 & $1.92(1.31-4.22$ & 0.001 \\
\hline \multicolumn{7}{|l|}{ CD4 count } \\
\hline 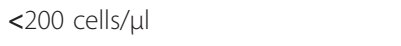 & $1(50.0)$ & $1(50.0)$ & & & & \\
\hline$\geq 200$ cells $/ \mu l$ & $1(16.7)$ & $5(83.3)$ & $4.05(3.27-5.01)$ & 0.029 & 2,94(2.44-6.98) & 0.000 \\
\hline \multicolumn{7}{|l|}{ Nature of perforation } \\
\hline Acute & $24(32.4)$ & $50(67.6)$ & & & & \\
\hline Chronic & $1(10.0)$ & $9(90.0)$ & $4.94(2.84-8.92)$ & 0.009 & $2.95(1.11-6.98)$ & 0.018 \\
\hline
\end{tabular}


Table 4 Predictors of mortality according to univariate and multivariate logistic regression analysis

\begin{tabular}{|c|c|c|c|c|c|c|}
\hline \multirow[t]{2}{*}{ Predictor (independent) variable } & \multirow[t]{2}{*}{ Survivors N (\%) } & \multirow[t]{2}{*}{ Non-survivors $\mathrm{n}(\%)$} & \multicolumn{2}{|c|}{ Univariate analysis } & \multicolumn{2}{|c|}{ Multivariate analysis } \\
\hline & & & O.R. (95\% C.I.) & p-value & (O.R. 95\% C.I.) & $\mathrm{p}$-value \\
\hline \multicolumn{7}{|l|}{ Age } \\
\hline$<40$ & $51(98.1)$ & $1(1.9)$ & & & & \\
\hline$\geq 40$ & $24(75.0)$ & $8(25.0)$ & $2.33(1.25-3.42)$ & 0.032 & $4.61(2.72-7.91)$ & 0.002 \\
\hline \multicolumn{7}{|l|}{ Sex } \\
\hline Male & $42(87.5)$ & $6(12.5)$ & & & & \\
\hline Female & $33(91.7)$ & $3(8.3)$ & $1.25(0.32-3.56)$ & 0.896 & $2.93(0.94-3.81)$ & 0.983 \\
\hline \multicolumn{7}{|l|}{ Premorbid illness } \\
\hline Yes & $2(33.3)$ & $4(66.7)$ & & & & \\
\hline No & $73(93.6$ & $5(6.4)$ & $6.21(1.49-7.01)$ & 0.039 & $3.78(2.98-7.90)$ & 0.017 \\
\hline \multicolumn{7}{|l|}{ Previous PUD } \\
\hline Yes & $23(88.0)$ & $3(12.0)$ & & & & \\
\hline No & $52(89.7)$ & $6(10.3)$ & $1.75(0.76-4.34)$ & 0.896 & $3.11(0.98-4.88)$ & 0.345 \\
\hline \multicolumn{7}{|l|}{ HIV status } \\
\hline Positive & $1(12.5)$ & $7(87.5)$ & & & & \\
\hline Negative & $74(97.4)$ & $2(2.6)$ & $0.56(0.12-0.86)$ & 0.005 & $1.74(1.21-4.98)$ & 0.001 \\
\hline \multicolumn{7}{|l|}{ CD 4+ count } \\
\hline$<200 \mathrm{cells} / \mu \mathrm{l}$ & $1(50.0)$ & $1(50.0)$ & & & & \\
\hline$\geq 200 \mathrm{cells} / \mu \mathrm{l}$ & $4(66.7)$ & $2(33.3)$ & $5.91(2.76-7.99)$ & 0.001 & $1.65(1,22-7.43)$ & 0.000 \\
\hline \multicolumn{7}{|l|}{ Duration of illness } \\
\hline$<24$ hours & $23(92.0)$ & $2(8.0)$ & & & & \\
\hline$\geq 24$ hours & $48(87.3)$ & $7(12.7)$ & $2.32(0.54-6.45)$ & 0.986 & $0.09(0.02-1.11)$ & 0.315 \\
\hline \multicolumn{7}{|c|}{ Shock on admission (SBP $<90 \mathrm{mmHg}$ ) } \\
\hline Yes & $28(77.8)$ & $8(22.2)$ & & & & \\
\hline No & $47(87.9)$ & $1(2.1)$ & $7.9(3.98-9.88)$ & 0.022 & $3,74(2,11-7.76)$ & 0.005 \\
\hline \multicolumn{7}{|l|}{ Timing of surgical treatment } \\
\hline$<48$ hours & $19(95.0)$ & $1(5.0)$ & & & & \\
\hline$\geq 48$ hours & $56(87.5)$ & $8(12.5 \%)$ & $2.87(2.11-7.21)$ & 0.044 & $2.91(1.22-6.66)$ & 0.028 \\
\hline \multicolumn{7}{|l|}{ Amount of fluid (mls } \\
\hline$<200$ & $19(95.0)$ & $1(5.0)$ & & & & \\
\hline$\geq 200$ & $56(87.5)$ & $8(12.5)$ & $0.67(0.23-4.65)$ & 0.982 & $1.61(0.89-2.73)$ & 0.067 \\
\hline \multicolumn{7}{|l|}{ Site of perforation } \\
\hline Duodenum & $72(93.4)$ & $5(6.6)$ & & & & \\
\hline Gastric & $2(33.3)$ & $4(66.7)$ & $5.81(3.33-6.92)$ & 0.012 & 1.35(1.11-3.86) & 0.018 \\
\hline \multicolumn{7}{|l|}{ Size of ulcer } \\
\hline Sealed & $7(100.0)$ & $0(0)$ & & & & \\
\hline$<5 \mathrm{~mm}$ & $12(92.3)$ & $1(7.7)$ & & & & \\
\hline$\geq 5 \mathrm{~mm}$ & $56(87.5)$ & $8(12.5)$ & $1.98(0.45-3.82)$ & 0.987 & $3.13(0.99-4.89)$ & 0.453 \\
\hline \multicolumn{7}{|l|}{ Complications } \\
\hline Present & $18(72.0)$ & $7(28.0)$ & & & & \\
\hline Absent & 57(96.6) & $2(3.4)$ & $1.98(1.54-7.93)$ & 0.005 & $2.86(2.22-6.45)$ & 0.011 \\
\hline
\end{tabular}

\section{Follow up of patients}

Out of 75 survivors, 46 (61.3\%) patients were followed up for 6 to 12 months after surgery. Depending upon their symptoms at each visit, patients were classified according to Visick grading system as follows: Visick grade I, 38 (82.6\%) patients, Visick grade II, 4 (8.7\%) patients, Visick grade III and IV, $2(4.3 \%)$ patients each respectively. One of patients $(2.2 \%)$ in Visick grade IV presented with re-perforation which necessitated reoperation.

\section{Discussion}

In this review, a total of 84 patients were enrolled over a five year period giving an average of 17 cases annually. This figure is similar to what was reported by Schein et al [19]. Mieny et al [20] in South Africa reported a low 
incidence of perforated PUD. These differences reflect differences in the rate of risk factors for perforated peptic ulcer disease from one country to another. The figures in our study may actually be an underestimate and the magnitude of the problem may not be apparent because of high number of patients excluded from this study.

In the present study, perforated peptic ulcer disease were found to be most common in the fourth decade of life and tended to affect more males than females, with a male to female ratio of 1.3:1 which is comparable with other studies in developing countries [3,21-23]. Our demographic profile is in sharp contrast to what is reported in developed countries where the majority of the patients are above 60 years and the incidence is higher in elderly females taking ulcerogenic medications [24]. Male predominance in this age group is attributed to excessive alcohol consumption and smoking among young males which is common in our environment. Alcohol consumption and smoking have been reported to be associated with increased risk for perforated peptic ulcer. Alcohol, as a noxious agent causes gastric mucosal damage, stimulates acid secretion and increases serum gastrin levels [25] and smoking inhibits pancreatic bicarbonate secretion, resulting in increased acidity in the duodenal bulb. It also inhibits the healing of duodenal ulcers $[21,26]$.

The rate of $\mathrm{H}$. pylori infection in patients with perforated peptic ulcers ranges from $50 \%-80 \%$ and $H$. pylori infection, as a risk factor for perforated PUD, appears to be more relevant in younger patients. This is in contrast to elderly patients, where NSAIDs may play a more significant etiologic role [27]. Determination of Helicobacter Pylori was not performed in our study due to lack of reagents.

Use of NSAID is an important cause of perforated peptic ulcer in the West. In our series, NSAID use as an offending cause could be attributable in only $10.7 \%$ patients. NSAID inhibit prostaglandin synthesis so further reducing gastric mucosal blood flow [27].

In agreement with other studies [3,24], more than sixty percent of patients had no past history suggestive of peptic ulcer disease and those with a known history of PUD were not on regular treatment. This is in sharp contrast to Nuhu et al in Nigeria who reported that $71 \%$ of cases had previous history of peptic ulcer disease [21]. It has been reported that in many developing countries, the diagnosis of PUD is first made in many instances after perforation [28]. The present study confirms this observation because more than sixty percent of the patients with perforation were not diagnosed previously as cases of PUD and therefore were not on treatment. Patients with no previous diagnosis of peptic ulcer have a higher risk of PUD perforation than patients with a known history of ulcer disease. This may be because preventative measures are more likely to have been taken in patients with a known history of ulcer. Furthermore, these patients are perhaps more likely to seek treatment earlier.

In this study, most of patients had either primary or no formal education and more than three quarter of them were unemployed. Similar occupational pattern was reported by others $[21,22]$. This observation has an implication on accessibility to health care facilities and awareness of the disease.

It has been reported that the interval between perforation and initiation of treatment is a better predictor of outcome. In the present study most of patients presented late more than 24 hours from the start of symptoms. This is in agreement with other studies in most developing countries [3,21-23,28]. Late presentation in our study may be attributed to lack of accessibility to health care facilities and lack of awareness of the disease. Hospital treatment is expensive and the patients may seek care only when the pain is unbearable. Patients may take medications in the pre-hospital period with hope that the symptom will abate. It is also possible that some clinicians managing the patients initially may not have considered perforation as a possible diagnosis.

More than $90 \%$ of our patients had classical presentation with sudden onset of sharp epigastric pain, as most of the studied patients were young aged in contradistinction to elderly patients in whom silent perforations usually occur $[3,29]$.

As reported in other studies $[5,9,30]$, associated premorbid illness was documented in $7.1 \%$ of cases. Associated premorbid illnesses have been reported to influence the outcome of patients with perforated peptic ulcers [5]. In the present study, associated premorbid illness predicted the outcome of patients with perforated peptic ulcers.

The prevalence of HIV infection among patients with perforated PUD in the present study was $9.5 \%$ that is higher than $6.5 \%$ [31] in the general population in Tanzania. This difference was statistically significant $(\mathrm{P}<$ 0.001). The high prevalence of HIV infection in our patients may be attributed to high percentage of the risk factors for HIV infection reported in the present study population. The overall HIV seroprevalence in our study may actually be an underestimate and the magnitude of the problem may not be apparent because many cases (8 patients) were excluded from the study due to failure to meet the inclusion criteria. We could not find any literature regarding the effect of HIV infection on the perforation rate and outcome in patient with perforated PUD. This calls for a need to research on this observation. In this study, HIV infection was found to be 
associated with high perforation rate and poor postoperative outcome. This observation calls for routine HIV screening in patients suspected to have perforated PUD.

In agreement with other studies [3,4,21,22,32], the diagnosis of perforated PUD in this study was made from history and identification of free air under the diaphragm in plain abdominal and chest radiographs, and the diagnosis was confirmed at laparotomy. The value of the radiological investigation has been compared with other writers and with current radiological techniques; $80-90 \%$ of cases are correctly diagnosed $[4,33]$. In case of perforated PUD ulcer, free intraperitoneal gas is less likely to be seen if the time interval between the perforation and radiological examination in short [4]. Recently, Computerized tomography (CT) scans with oral contrast are now considered the reliable method of detecting small pneumoperitonium before surgery and the gold standard for the diagnosis of a perforation [34,35]. Abdominal ultrasonography has also been found to be superior to plan radiographs in the diagnosis of free intra-peritoneal air [35]. None of these imaging studies were used in the diagnosis of free intra-peritoneal air in our study. We relied on plain radiographs of the abdominal/chest to establish the diagnosis of free intraperitoneal air which was demonstrated in $65.8 \%$ of cases. We could not establish, in our study, the reason for the low detection rate of free air under the diaphragm.

In our study, duodenal ulcer perforation was the most common type of perforation with a duodenal to gastric ulcer ratio of $12.7: 1$. This is comparable to a study in Kenya which reported a duodenal to gastric ulcer ratio of 11.5:1 [32]. A high duodenal to gastric ulcer ratio of 25:1 was reported in Sudan [36]. A study in Ghana reported high incidence of gastric ulcer perforations than duodenal ulcer perforation [37]. Low duodenal to gastric ulcer ratios of $3: 1$ to $4: 1$ have been reported from the western world [32,37]. Gastric ulcer is considered a rare disease in Africa being 6-30 times less common than duodenal ulcers $[37,38]$. There was no obvious explanation to account for these duodenal to gastric ulcer ratio differences.

In this study, Graham's omental patch of the perforations with either a pedicled omental patch or a free graft of omentum was the operation of choice in our centre. Similar surgical treatment pattern was reported in other studies $[3,4,21,22]$. This is a rapid, easy and lifeserving surgical procedure that has been shown to be effective with acceptable mortality and morbidity $[22,39]$. Although this procedure has been associated with ulcer recurrence rates of up to $40 \%$ in some series, Graham's omental patch of PUD perforations remains a surgical procedure of choice in most centres and to avoid recurrence the procedure should be followed by eradication of $H$. pylori [22,40]. Simple closure of perforation with omental patch and the use of proton pump inhibitors have changed the traditional definitive peptic ulcer surgery of truncal vagotomy and drainage procedures [41]. Definitive surgery is indicated only for those who are reasonably fit and presented early to the hospital for surgery [22]. Definitive peptic ulcer surgery increases operative time, exposes the patient to prolonged anaesthesia and also increases the risk of postoperative complications. This is especially true in developing countries including Africa where patients often present late with severe generalized peritonitis [23]. In the present study, only one patient who presented early with stable haemodynamic state underwent definitive peptic ulcer surgery of truncal vagotomy and drainage. Recently, laparoscopic repair of perforated peptic ulcer has also been reported, [42] and this is believed to help reduce postoperative morbidity and mortality [43].

The laparoscopic technique in closure of perforated peptic ulcers is being practiced in several centres in developed countries $[42,43]$, it has not yet been tried in any of our hospitals in this country.

Overall complications rate in this series was $29.8 \%$ which is comparable to what was reported by others $[4,44]$. High complications rate was reported by MontalvoJavé et al [6]. This difference in complication rates can be explained by differences in antibiotic coverage, meticulous preoperative care and proper resuscitation of the patients before operation, improved anesthesia and somewhat better hospital environment. In keeping with other studies $[21,22,39]$, surgical site infection was the most common complication. High rate of surgical site infection in the present study may be attributed to contamination of the laparotomy wound during the surgical procedure.

Perforated peptic ulcer is a serious condition with an overall reported mortality of $5 \%-25 \%$, rising to as high as $50 \%$ with age $[5-7,9,11,44]$. In this study mortality rate was high in patients who had age $\geq 40$ years, delayed presentation ( $>24 \mathrm{hrs}$ ), shock at admission (systolic BP $<90 \mathrm{mmHg}$ ), HIV positivity, low CD4 count (< 200 cells $/ \mu \mathrm{l}$ ) and concomitant diseases. Also gastric ulcers were associated with an increased mortality risk. Boey's score, which is a score based on scoring factors as shock on admission, confounding medical illness, and prolonged perforation, has been found to be a useful tool in predicting outcome [11]. In this study, Boey score was a good predictor of both mortality and postoperative complication and therefore should be used in our setting as a tool for predicting outcome in patients with perforated peptic ulcers.

Since tests for detecting $H$. Pylori was not possible in our patients due to logistic problems, we did not take 
this into consideration in our discussion. However the use of the 'triple regime' produced excellent results in $82.6 \%$ of our patients which is comparable to the results from recent studies [3. 4, 21, 22, 45] which have successfully used simple closure followed by eradication of H-Pylori as a treatment for perforated peptic ulcer. This is in contrast to the earlier studies $[46,47]$ which reported emergency definitive surgery as a means to prevent recurrence and re-operation rates. These findings are extremely important for developing countries like Tanzania where delay in presentation often prevents any attempt at definitive surgery.

Before generalizing the results of our study several important issues need to be addressed. First, since all the subjects in the present study underwent pen repair, results from this study may not fully represent those after laparoscopic repair. Second, we did not study the association of $H$. pylori with the postoperative outcomes because of lack of necessary facilities at the study center. Third, data obtained retrospectively and failure to detect HIV infection during window period may have underestimated the prevalence of HIV infection. Fourth, since our duration of postoperative follow up was relatively short, we could not estimate the long term effect of Graham's omental patch.

\section{Conclusion}

Perforation of peptic ulcer remains a frequent clinical problem in our environment predominantly affecting young males not known to suffer from PUD. Simple closure with omental patch followed by Helicobacter pylori eradication was effective with excellent results in majority of cases despite patients' late presentation in our center.

\section{Acknowledgements}

The authors are grateful to our senior house officers (residents) in the Department of Surgery for their assistance in data collection and to all those who were involved in the care of our patients.

\section{Author details}

${ }^{1}$ Department of Surgery, Weill-Bugando University College of Health Sciences, Mwanza, Tanzania. ${ }^{2}$ Department of Internal Medicine, WeillBugando University College of Health Sciences, Mwanza, Tanzania. ${ }^{3}$ Department of Surgery, Muhimbili University of Health and Allied Sciences, Dar Es Salaam, Tanzania.

\section{Authors' contributions}

PLC - study design, literature search, data analysis, manuscript writing \& editing and submission of the manuscript, JBM, MK, MDM, HMJ, RK, ABC participated in data analysis, manuscript writing \& editing and JMGsupervised and coordinated the manuscript writing \& editing. All the authors read and approved the final manuscript.

\section{Competing interests}

The authors declare that they have no competing interests. The study had no external funding. Operational costs were met by authors
Received: 10 July 2011 Accepted: 26 August 2011

Published: 26 August 2011

\section{References}

1. Türkdoğan MK, Hekim H, Tuncer İ, Aksoy H: The epidemiological and endoscopic aspects of peptic ulcer disease in Van region. Eastern Journal of Medicine 1999, 4(1):6-9.

2. Isenberg Jl, McQuaid KR, Laine L, Rubin W: Acid-peptic disorders. In Textbook of Gastroenterology. Edited by: Yamada T. J.B Lıppıncott comp., Philadelphia; 1991:1241-98, ch.61.

3. Elnagib E, Mahadi SE, Mohamed E, Ahmed ME: Perforated peptic ulcer in Khartoum. Khartoum Medical Journal 2008, 1(2):62-64.

4. Khan SH, Aziz SA, Ul-Haq MI: Perforated peptic ulcers: A review of 36 cases. Professional Med J 2011, 18(1):124-127.

5. Makela JT, Kiviniemi H, Ohtonen P, Laitinen SO: Factors That Predict Morbidity and Mortality in Patients with Perforated Peptic Ulcers. Eur $J$ Surg 2002, 168:446-451.

6. Montalvo-Javé EE, Corres-Sillas O, César Athié-Gutiérrez C: Factors associated with postoperative complications and mortality in perforated peptic ulcer. Cir Cir 2011, 79:128-135.

7. Testini M, Portincasa P, Piccinni G, Lissidini G, Pellegrini F, Greco L: Significant factors associated with fatal outcome in emergency open surgery for perforated peptic ulcer. World J Gastroenterol 2003, 9:2338-2340.

8. Soll AH: Peptic ulcer and its complications. In Sleisinger \& Fordtran's Gastrointestinal and Liver Disease: Pathophysiology, Diagnosis, Management. 6 edition. Edited by: Feldman M, Scharschmidt BF, Sleisenger MH. Philadelphia, PA: W.B. Saunders; 1998:620-678.

9. Rajesh V, Sarathchandra S, Smile SR: Risk factors predicting operative mortality in perforated peptic ulcer disease. Trop Gastroenterol 2003, 24:148-150.

10. Hermansson M, Von Holstein CS, Zilling T: Surgical approach and prognostic factors after peptic ulcer perforation. Eur J Surg 1999, 165:566-572.

11. Boey J, Choi KY, Alagaratnam TT, Poon A: Risk stratification in perforated duodenal ulcers. A prospective validation of predictive factors. Ann Surg 1986, 205:22-26.

12. Kudva MV, Thein-Htut T: Profile of Peptic Ulcer Disease in Malaysia. Sing Med J 1988, 29:544-547.

13. Hill AG: The management of perforated peptic ulcer in a resource poor environment. East Afr Med J 2001, 78(8):346-348.

14. Windsor JA, Hill AG: The management of perforated peptic ulcer. N Z Med J 1995, 47-48.

15. Cuschieri A: Disorders of stomach and duodenum. In Essential surgical practice.. 4 edition. Edited by: Cuschieri A, Steel RJC, Moosa AR. London: Arnold; 2002:261-319.

16. Mehboob M, Khan JA, Rehman Shafiq-ur, Saleem SM, Abdul Qayyum A: Peptic duodenal perforation-an audit. JCPSP 2000, 10:101-3.

17. Gutierrez de La pena C, Merquez R, Fakih F, Dominguez-Adame E, Medina J: Simple closure or vagotomy and pyloroplasty for the treatment of a perforated duodenal ulcer comparison of results. Dig surg 2000, 17:225.

18. Visick AH: Measured radical gastrectomy. Review of operations for peptic ulcer. Lancet 1948, 1:505-510.

19. Schein M, Saadia R, Decker GA: Perforated peptic ulcer at the J. G. Strijdom Hospital: A retrospective study of 99 patients. S Afr Med J 1986, 70(5):21-23.

20. Mieny CJ, Kopelowitz W, Colsen P: Management of perforated peptic ulcer. S Air] Surg 1974, 12:27-29.

21. Nuhu A, Madziga AG, Gali BM: Acute perforated duodenal ulcer in Maiduguri. The Internet Journal of Surgery 2009, 21:1.

22. Nasio NA, Saidi H: Perforated Peptic Ulcer Disease at Kenyatta National Hospital, Nairobi. East and Central African Journal of Surgery 2009, 14(1):13-16.

23. Tessema E, Meskel $Y$, Kotiss B: Perforated peptic ulcer in Tikur Anbessa Hospital. Ethiop Med Journal 2005, 43(1):9-13.

24. Kang JY, Elders A, Majeed A: Recent trend in hospital admission and mortality rate for peptic ulcer in Scotland 1982 - 2002. Aliment Pharmacol Ther 2006, 24(1):65-79. 
25. Türkdoğan MK, Hekim H, Tuncer I, Aksoy H: The epidemiological and endoscopic aspects of peptic ulcer disease in Van region. Eastern Journal of Medicine 1999, 4(1):6-9.

26. Stabile BE, Passaro EP: Duodenal ulcer: a disease in evolution. Curr Probl Surg 1984, 21:1-79.

27. Collier DS, Pain JA: Non-steroidal anti-inflammatory drugs and peptic ulcer perforation. Gut 1985, 26:359-363.

28. Ajao OG: Perforated duodenal ulcer in a tropical African population. $J$ Natl Med Assoc 1979, 71:272-3.

29. Jeffrey AN, Randal R, Alfred EC, Stephen FH, Robert WT: 'Surgery basic science and clinical evidence' USA: Donnelley and Sons, Willard OH; 2001, 489-500.

30. Bas G, Eryilmaz R, Okan I, Sahin M: Risk Factors of Morbidity and Mortality in Patients with Perforated Peptic Ulcer. Acta Chir Belg 2008, 108:424-427.

31. Urassa M, Isingo R, Kumogola Y, Mwidunda P, Helelwa M, Changulucha J, Mngara J, Zaba B, Calleja T, Slaymaker E: Effect of PMTCT availability on choice of ANC in Mwanza and Magu districts and its impact on HIV sentinel surveillance. Report of ANC surveillance Mwanza and Magu Districts, Tanzania 2007, (Unpubl.).

32. Kuremu RT: Surgical management of peptic ulcer disease. East Afr Med J 2002, 76(9):454-456.

33. Lee CW, Yip AW, Lam KH: Pneumogastrogram in the diagnosis of perforated peptic ulcer. Aust N Z J-Surg 1993, 63:459-61.

34. Amela S, Serif B, Lidija L: Early radiological diagnostics of gastrointestinal infection in the management of peptic ulcer perforation. Radiol Oncol 2006, 40(2):67-72.

35. Chen SC, Yen ZS, Wang HP, Lin FY, Hsu CY, Chen WJ: Ultrasonography is superior to plain radiography in the diagnosis of pneumoperitonium. $\mathrm{Br}$ J Surg 2002, 89:351-354.

36. Fedail S, Araba BMO, Homeda MM, Ghandour ZM: Upper gastrointestinal endoscopy in Sudan: Analysis of 2500 endoscopies. 1983, 2:897-9.

37. Ohene-Yeboah M, Togbe B: Perforated gastric and duodenal ulcers in an urban African population. West Afr J Med 2006, 25(3):205-211.

38. Umerah BC, Singarayar J, Ramzan MK: Incidence of peptic ulcer in the Zambian African- a radiological study. Med J Zambia 1987, 12:117-118.

39. Khalil AR, Yunas M, Qutbe AJ, Nisar W, Imran M: Grahm's omentopexy in closure of perforated duodenal ulcer. J Med Sci 2010, 18(2):87-90.

40. Sharma SS, Manju RM, Sharma SM, Kulkarni H: A prospective cohort study of postoperative complications in the management of perforated peptic ulcer. BMC Surgery 2006, 6:8.

41. Gurleyik E: Changing trend in emergency surgery for perforated duodenal ulcer. J Coll Physicians Surg Pak 2003, 13:708-10.

42. Beena B, Vaidya, Chaitanya : Laparoscopic repair of perforated peptic ulcer with delayed Presentation. Journal of laparoendoscopic and advanced surgical technique 2009, 19(2):153-156.

43. Song KY, Kim TH, Kim SN, Park CH: Laparoscopic repair of perforated duodenal ulcer: the simple one - stitch suture with omental patch technique. Surg Endoscope 2008, 22(7):1632-5.

44. Lee FY, Leung KL, Lai BS, Ng SS, Dexter S, Lau WY: Predicting mortality and morbidity of patients operated on for perforated peptic ulcers. Arch Surg 2001, 139:90-94.

45. Gupta BS, Talukdar RN, Neupane HC: Cases of Perforated Duodenal Ulcer treated in College of Medical Sciences, Bharatpur over a period of one year. Kathmandu University Medical Journal 2003, 1(3):166-169.

46. Jordan GL, De Bakey ME: Surgical Management of perforated peptic ulcer. Ann Surg 1974, 179:628-33.

47. Gray JG, Roberts AK: Definitive emergency treatment of perforated duodenal ulcer. Surg Gynaecol Obstet 1976, 143:890-4.

doi:10.1186/1749-7922-6-31

Cite this article as: Chalya et al: Clinical profile and outcome of surgical treatment of perforated peptic ulcers in Northwestern Tanzania: A tertiary hospital experience. World Journal of Emergency Surgery 2011 6:31.

\section{Submit your next manuscript to BioMed Central and take full advantage of:}

- Convenient online submission

- Thorough peer review

- No space constraints or color figure charges

- Immediate publication on acceptance

- Inclusion in PubMed, CAS, Scopus and Google Scholar

- Research which is freely available for redistribution 